\title{
Substitution of Rare Earths in Magnesium Alloys
}

\section{Roland Hoppe ${ }^{1, a^{*}}$, Gerrit Kurz ${ }^{1, b}$, Dietmar Letzig ${ }^{1, c}$}

\author{
${ }^{1}$ Magnesium Innovation Centre; Max-Planck-Straße 1, 21502 Geesthacht, Germany \\ a'Roland.Hoppe@HZG.de, 'berrit.Kurz@HZG.de, 'Dietmar.Letzig@HZG.de
}

Keywords: Magnesium, twin roll casting, magnesium sheet, calcium containing alloys

\begin{abstract}
Magnesium alloys containing rare earth elements have better properties in terms of formability, strength and corrosion resistance. Due to the tight supply situation these elements should be substituted partially or complete, for example by calcium. Microstructural studies of cast alloys of new compositions, and the influence of various heat treatments on their microstructure are investigated. The mechanical properties of the rolled materials are also presented and discussed. The works presented in this paper are results of the ongoing BMBF project SubSEEMag.
\end{abstract}

\section{Introduction}

The application of rare earth elements in Magnesium alloys leads to a significant increase of strength, ductility, creep resistance and corrosion resistance compared to classic alloys like the AZ31 [1]. Because of the strategic importance of these elements, which leads to economical dependencies, they are classified as a critical resource group. In addition there are environmental problems producing these elements which should be avoided in terms of sustainability. Aim of this project is to design new alloys which meet the properties of rare earth containing alloys or even surpass them. There is a special view on the capability of sheet material to be plastically deformed at room temperature. The poor plastic deformability of common magnesium sheet materials is caused by its pronounced rolling texture and is the reason why until now there are only a few applications of magnesium sheets especially in the automotive industry. The reason for this is the limited number of deformation systems that could be activated in magnesium crystals for plastic deformation at low temperatures $[2,3]$. Rare earth elements containing magnesium alloys show the demanded randomized texture and fine-grained microstructure [4-6]. There are already applications of magnesium parts in a car. Some of them like wheels and housings are cast parts as they are well known. Others like the roof are sheet applications. These sheet components are not easy to produce with the standard AZ31-alloy. It is time- and therefore cost intensive to deform flat sheet material of this alloy to the finished product.

In consequence rare earth free magnesium alloys with a weaker rolling texture have to be found to meet the demands of the automotive industry. In cooperation with the project partners there are a number of alloys selected to be tested [Table 1]. Most of them are calcium containing alloys, because adding $\mathrm{Ca}$ to $\mathrm{Mg}-\mathrm{Zn}$ containing $\mathrm{Mg}$-alloys leads to a texture evolution similar to $\mathrm{RE}$ containing alloys [7,8]. Additionally the common AZ31-alloy was tested as a benchmark. These alloys were cast in laboratory scale. The billets with a size of $105 \mathrm{~mm}$ in diameter and a length of $220 \mathrm{~mm}$ were cast in a modified gravity casting process.

Table 1: Alloy composition and heat treatment

\begin{tabular}{|l|l|l|}
\hline Alloy & Alloy composition & Heat treatment \\
\hline ZMX210 & $2 \mathrm{~m} \% \mathrm{Zn}, 1 \mathrm{~m} \% \mathrm{Mn},<1 \mathrm{~m} \% \mathrm{Ca}$ & $350^{\circ} \mathrm{C} / 16 \mathrm{~h}$ \\
\hline ZAX210 & $2 \mathrm{~m} \% \mathrm{Zn}, 1 \mathrm{~m} \% \mathrm{Al},<1 \mathrm{~m} \% \mathrm{Ca}$ & $450^{\circ} \mathrm{C} / 16 \mathrm{~h}$ \\
\hline MX20 & $2 \mathrm{~m} \% \mathrm{Mn},<1 \mathrm{~m} \% \mathrm{Ca}$ & $450^{\circ} \mathrm{C} / 16 \mathrm{~h}$ \\
\hline MX21 & $2 \mathrm{~m} \% \mathrm{Mn}, 1 \mathrm{~m} \% \mathrm{Ca}$ & $450^{\circ} \mathrm{C} / 16 \mathrm{~h}$ \\
\hline ZA21 & $2 \mathrm{~m} \% \mathrm{Zn}, 1 \mathrm{~m} \% \mathrm{Al}$ & $400^{\circ} \mathrm{C} / 16 \mathrm{~h}$ \\
\hline AZ31 & $3 \mathrm{~m} \% \mathrm{Al}, 1 \mathrm{~m} \% \mathrm{Zn}$ & $450^{\circ} \mathrm{C} / 16 \mathrm{~h}$ \\
\hline
\end{tabular}


For each alloy there was a tailored heat treatment found, that leads to an optimized microstructure where precipitations especially at the grain boundaries are gone in solid solution and dendritic structures in the grains disappeared. In table 1 there are all these alloys listed up with its composition and heat treatment. After the heat treatment all these alloys were rolled to sheets and mechanical tests were performed to determine the mechanical properties. The tests were performed according to ISO 6892-1. The microstructure and texture of the tested specimen were analyzed and the results discussed in terms of their influence on the observed mechanical properties.

\section{AZ31}

The AZ31 alloy was tested as a benchmark. The experimental proceeding will be shown here as it was done to all the alloys tested in this project. Out of the cast billet rolling specimen were prepared with dimensions of $20 \mathrm{~mm}$ thickness by $70 \mathrm{~mm}$ with and $140 \mathrm{~mm}$ in length. Those heat treated slabs were rolled down from $140 \mathrm{~mm}$ in rolling direction and $20 \mathrm{~mm}$ thickness to final gauge of app. $1.7 \mathrm{~mm}$. The rolling temperature was equal to the annealing temperature. In this case it was $450{ }^{\circ} \mathrm{C}$. Before the first rolling pass the specimen were heated up for 30 minutes. Between each rolling step they were heated up again starting with duration of 15 minutes for each period. After step \#8 the thickness of the strip was below $7 \mathrm{~mm}$ and therefore the heating duration could be reduced to 10 minutes. The initial deformation grade at this rolling procedure was $\varphi=0.1$ and it was increased to $\varphi=0.2$ at step 5 and finally to $\varphi=0.3$ from step 12 on. After rolling the microstructure of the produced sheet material was inspected using optical microscopy. Standard metallographic sample preparation techniques were employed and an etchant based on picric acid was used to reveal grains and grain boundaries [9] (Fig. 1). Specimens for texture measurements were prepared out of the rolled sheet. Using a Panalytical X-ray diffractometer the pole figures were measured up to a tilt of $70^{\circ}$. This allowed recalculation of full pole figures based on an MTEX


texture of the strips at the mid plane of the sheet. The AZ31 alloy shows the typical pronounced rolling texture with a maximum of 9.6 in the (0001) pole figure (Fig. 2a).
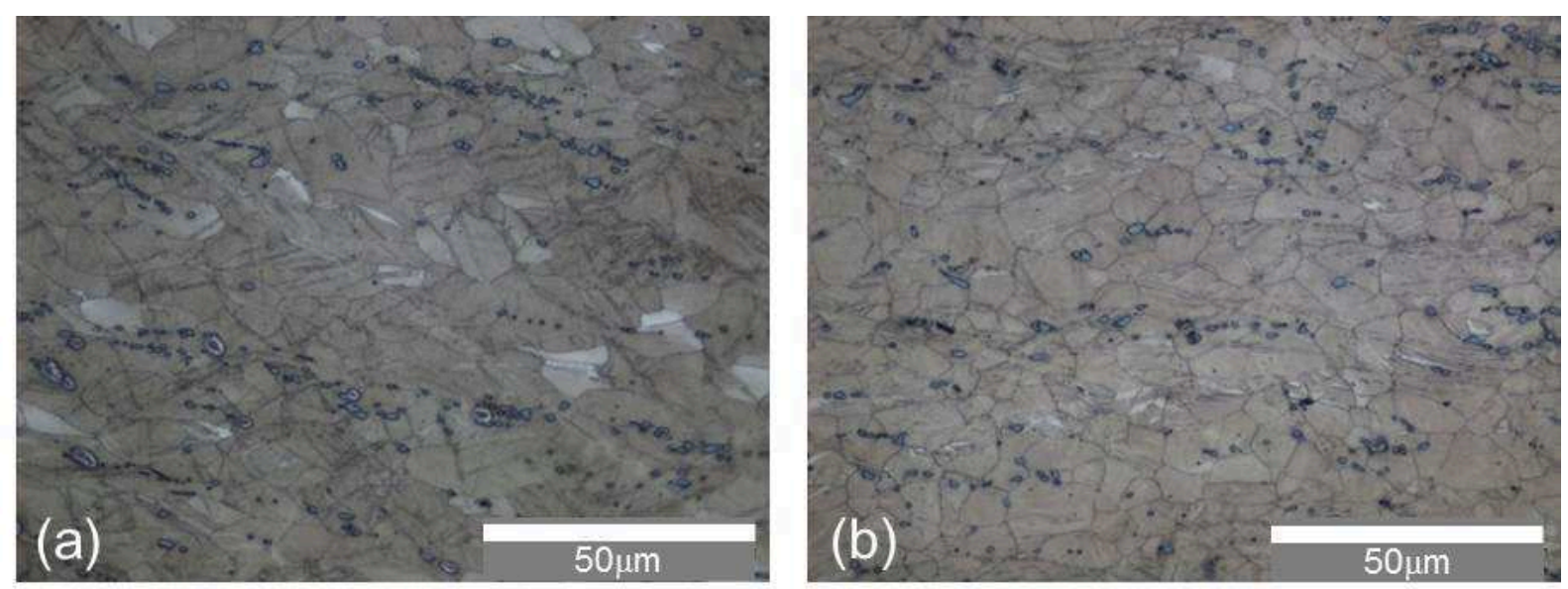

Figure 1: Microstructure of AZ31, rolling temperature $450{ }^{\circ} \mathrm{C}$ in rolling direction (a) and transverse direction (b)

Tensile test specimen were prepared out of the rolled sheet with dimensions of $12.5 \mathrm{~mm}$ by $50 \mathrm{~mm}$ according to DIN 50125-H. Before performing tests on those specimen they were heat treated for $1 \mathrm{~h}$ at the same temperature the sheet was rolled before. The uniaxial tensile test was performed according to ISO6892-1 at room temperature with a strain rate of $\mathrm{d} / \mathrm{dt}=10^{-3} \mathrm{~s}^{-1}$. In these tests performed on two specimen the AZ31 shows the expected behavior with an average flow stress of $154 \mathrm{MPa}$, ultimate stress of $253 \mathrm{MPa}$ at $14.2 \%$ elongation and an average plastic fracture strain of $14.9 \%$ (Fig. 2b). 


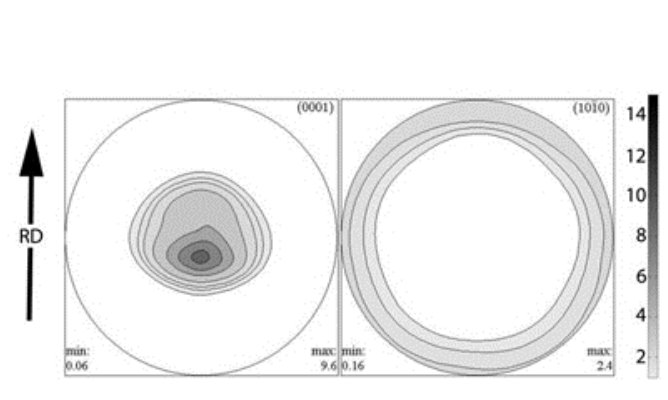

(a)



(b)

Figure 2: Texture of the AZ31 sheets rolled at $450{ }^{\circ} \mathrm{C}$ (a) and stress-strain curves of AZ31. Both specimen rolled at $450{ }^{\circ} \mathrm{C}$ and annealed at $450{ }^{\circ} \mathrm{C}(\mathrm{b})$

\section{ZA21}

In the as cast state the ZA21 alloy shows a globular microstructure with large grains, and a high amount of small precipitates which are homogenous distributed inside the grains. After the heat treatment for $16 \mathrm{~h}$ at $400{ }^{\circ} \mathrm{C}$ the grain size did not change significantly, but the precipitations disappeared nearly completely. Rolling the ZA21 at $350{ }^{\circ} \mathrm{C}$ resulted in a sheet with small cracks at the edges, but with the temperature increased to $400{ }^{\circ} \mathrm{C}$ they did not show up again. The microstructure shows severe plastic deformation localized mainly in the center of the sheet resulting in very fine grains by the effect of dynamic recrystallization. The (0001) pole figure of the ZA21 shows a basal texture with a double peak in rolling direction (Fig. 3a). The strain test results in a flow stress of about $96 \mathrm{MPa}$, an ultimate stress of $214 \mathrm{MPa}$ at $18 \%$ elongation and a fracture elongation of $19 \%$ (Fig. 3b).

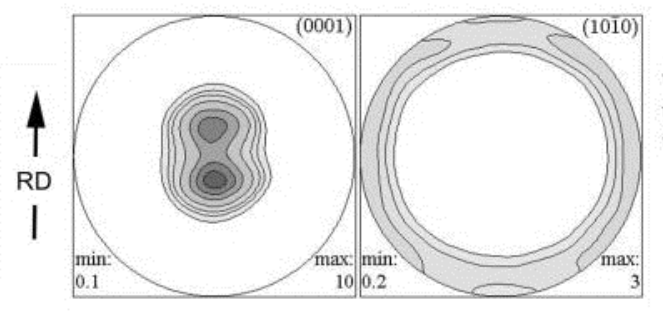

(a)

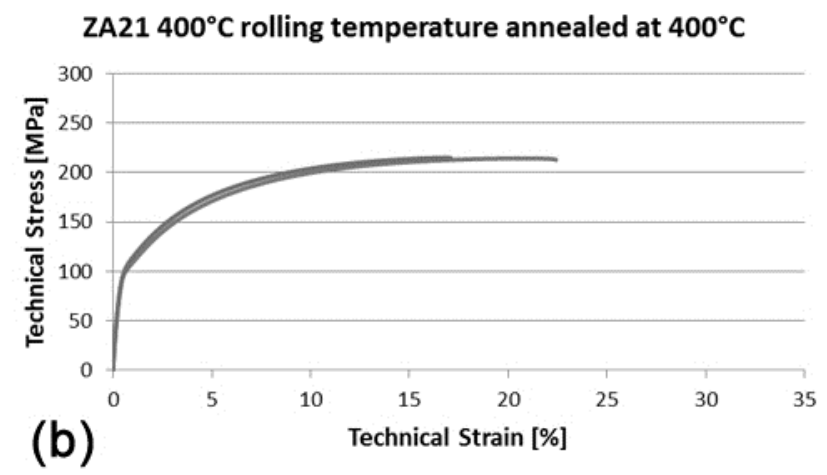

Figure 3:Texture (a) and stress-strain curves of ZA21. Both specimen rolled at $400{ }^{\circ} \mathrm{C}$ and annealed at $400{ }^{\circ} \mathrm{C}(\mathrm{b})$

\section{ZAX210}

The alloy ZAX210 which differs from the before described ZA21 only by a small amount of Calcium added, shows nearly the same microstructure in the as cast condition. The coarse microstructure with grains even bigger than $1 \mathrm{~mm}$ and a big amount of small precipitations inside these grains changes the same way during the $16 \mathrm{~h} / 450{ }^{\circ} \mathrm{C}$ heat treatment. The number of precipitations decreases significantly but those remaining grow slightly. Dendritic structures observed inside the grains have as well disappeared afterwards. After a not successful first rolling trial at $450{ }^{\circ} \mathrm{C}$ the temperature was reduced down to $350{ }^{\circ} \mathrm{C}$. This trial was successful, but because of some hot cracks at the sides of the strip the temperature was finally reduced to $300{ }^{\circ} \mathrm{C}$ and so the number of hot cracks was reduced. 


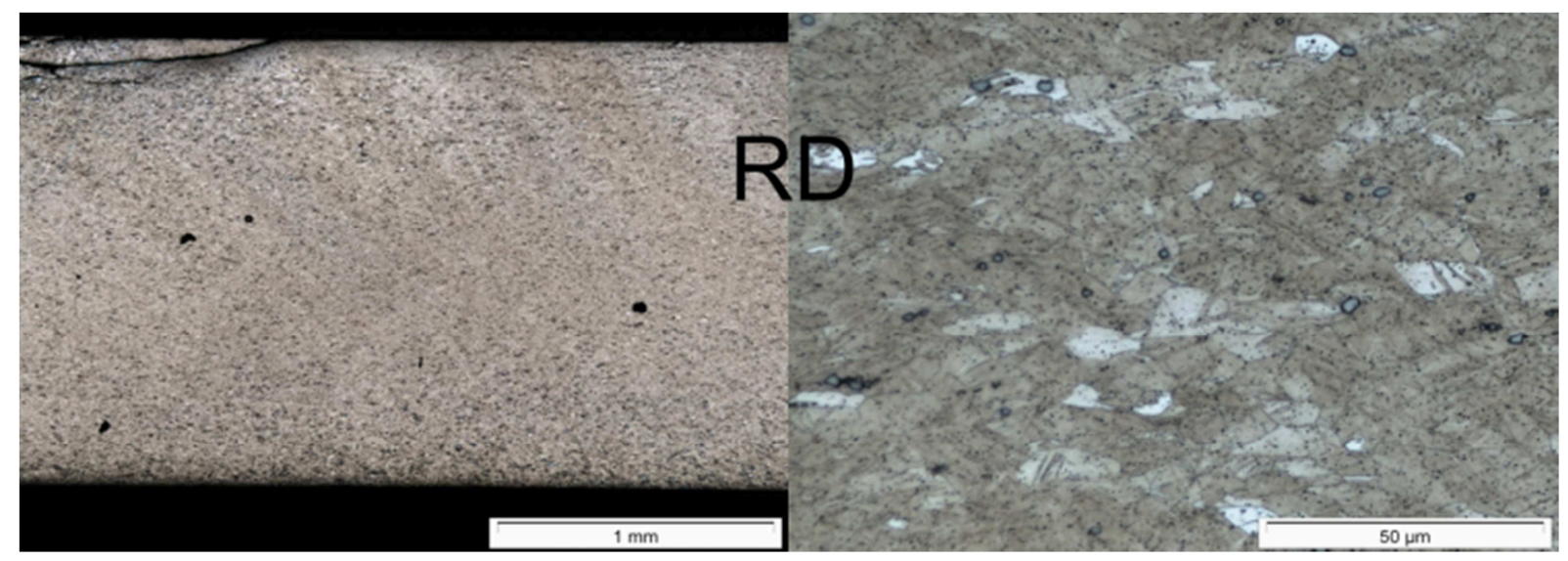

Figure 4: Microstructure of the ZAX210 sheets rolled at $350^{\circ} \mathrm{C}$

In comparison to the before discussed ZA21 alloy the microstructure of the ZAX210 rolled at $350{ }^{\circ} \mathrm{C}$ is very fine grained and homogenous without any signs of local deformation. The microstructure seems not to be fully recrystallized during the rolling process (Fig. 4). The texture measured after rolling is weaker compared to those of AZ31 and ZA21. It has a (0001) maximum of 7.6, two peaks along the rolling direction (RD) and is enlarged in the transversal direction (TD) (Fig. 5a). This is similar to textures observed at rare earth containing Mg alloys like the ZE10. Performing tensile tests on this material, the ZAX210 shows the good formability that is expected because of the mentioned texture. The addition of a small amount of Ca to the ZA21 improves the formability without even lowering the strength. With a flow stress of $154 \mathrm{MPa}$, an ultimate stress of $245 \mathrm{MPa}$ at $18.5 \%$ elongation and a fracture elongation of $27.1 \%$ (Fig. 5b), this alloy outperformed all the other inspected alloys. This makes it one of the most promising candidates for the further project.



(a)



Figure 5: Texture (a) and stress-strain curves of ZAX210. Both specimen rolled at $350{ }^{\circ} \mathrm{C}$ and annealed at $350{ }^{\circ} \mathrm{C}(\mathrm{b})$

\section{ZMX210}

In the ZMX 210 alloy compared to the ZAX210 aluminum is replaced by manganese. The micrograph shows a fine grained homogenous microstructure. After heat treatment at $350{ }^{\circ} \mathrm{C}$ for $16 \mathrm{~h}$ the precipitates located at the grain boundaries and inside the grains are reduced. The grain size is not influenced by the temperature. The slap was destroyed during the first rolling pass at $400{ }^{\circ} \mathrm{C}$ because of hot cracks. Reducing the rolling temperature to $300{ }^{\circ} \mathrm{C}$ gives same result. This is probably because of the existence of the $\mathrm{Mg}_{6} \mathrm{Ca}_{2} \mathrm{Zn}_{3}$ phase in this material. This phase has a melting point of around $400{ }^{\circ} \mathrm{C}$, so that the additional energy induced by the severe plastic deformation during the rolling process could lead to hot cracks. 


\section{MX20 / MX21}

The last described magnesium alloys are manganese and calcium containing ones. They differ in the amount of calcium added. In case of the MX21 there is more than $1 \mathrm{~m} \%$ of calcium added. In case of the MX20 the Ca-content is below $1 \mathrm{~m} \%$. The microstructure of the MX21 alloy is finer and more homogenous, but there are dendritic structures observed inside the grains. The precipitates in the MX21 are more located on the grain boundaries. After the heat treatment for $16 \mathrm{~h}$ at the temperature of $450{ }^{\circ} \mathrm{C}$ these precipitations are reduced and the dendritic structures could not be seen anymore. In both cases the grain size is the same after the heat treatment. Both alloys were rolled at $450{ }^{\circ} \mathrm{C}$. There were no problems observed during this process, so both alloys could be rolled down to sheets with a thickness of $1.7 \mathrm{~mm}$ without any cracks. After rolling a fine grained homogenous microstructure was achieved in both alloys. Precipitates were found in both alloys, but there are more of them in the MX21 and they are aligned in small lines. A medium grain size of $15 \mu \mathrm{m}$ in the MX20 alloy, and $26 \mu \mathrm{m}$ in the MX21 was found (Fig. 6). The higher Ca content of the MX21 alloys reduces the intensity of the (0001) texture to a maximum of $\mathrm{I}_{\max }=8.4$, which is slightly smaller than the maximum of $I_{\max }=9.1$ of the MX20 alloy (Fig. 7a). There are no great differences in the mechanical properties observed. Even though the MX21 had a weaker texture the MX20 shows a better deformability compared to the MX21 which had a fracture strain of $7.8 \%$ (Fig. 7b). The finer microstructure of the MX21 did not result in a higher strength. It was absolutely comparable (213 MPa vs. $209 \mathrm{MPa}$ ).

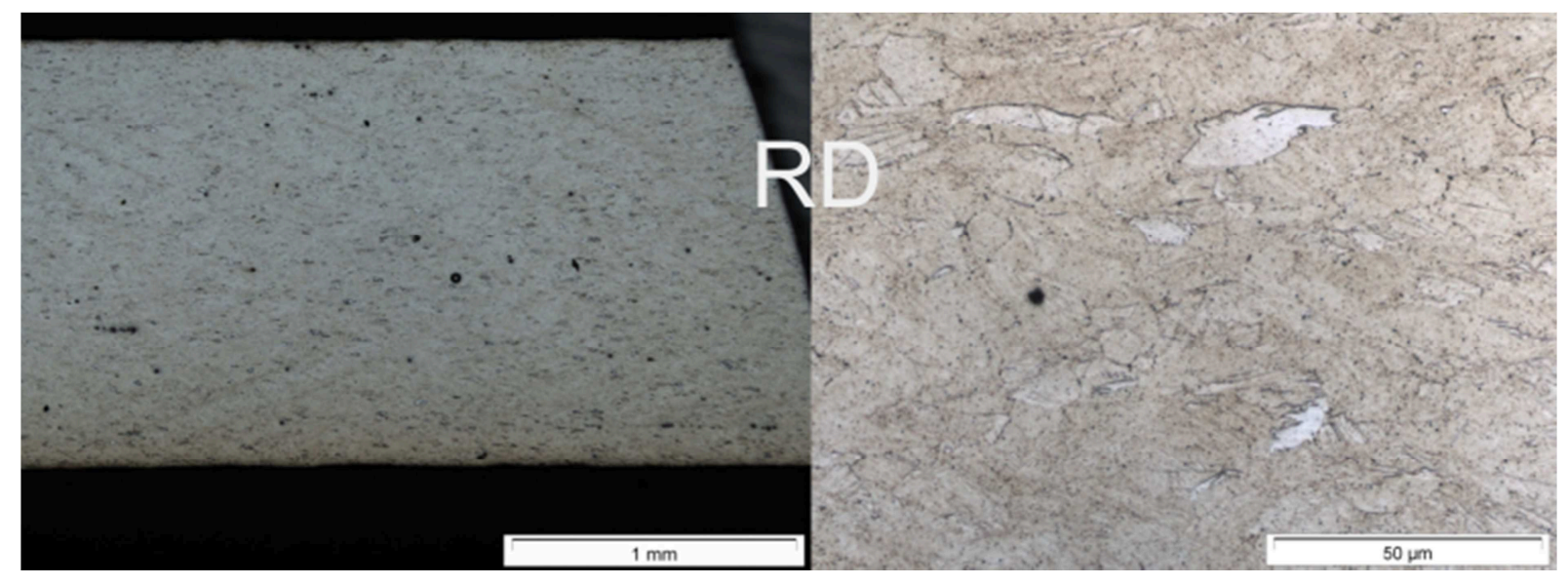

Figure 6: Microstructure of the MX20 sheets rolled at $450{ }^{\circ} \mathrm{C}$

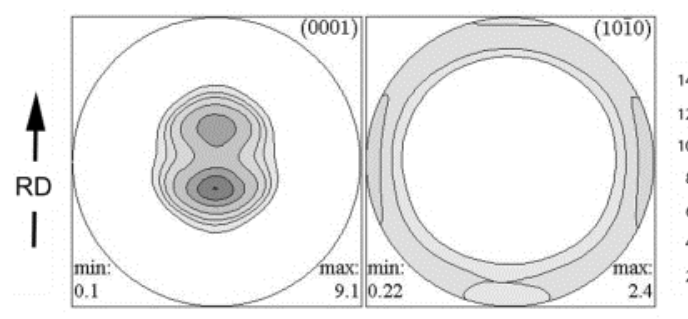

(a)
$\mathrm{MX20} 450^{\circ} \mathrm{C}$ rolling temperature annealed at $450^{\circ} \mathrm{C}$

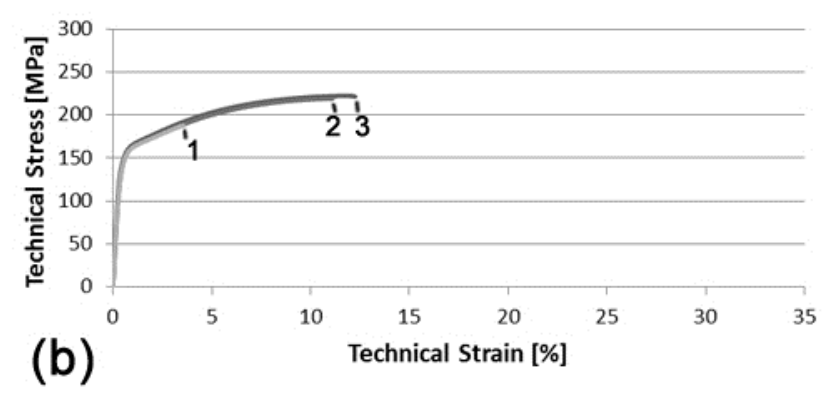

Figure 7: Texture (a) and stress-strain curves of MX20. All three specimen rolled at $450{ }^{\circ} \mathrm{C}$ and annealed at $450{ }^{\circ} \mathrm{C}(\mathrm{b})$ 


\section{Conclusions}

The heat treatment tests show the influence of different temperatures on the various microstructures in the as cast state. All the investigated alloys could be rolled except the $\mathrm{Zn}, \mathrm{Mn}$ and Ca containing ZMX210, which probably results out of the existence on the $\mathrm{Mg}_{6} \mathrm{Ca}_{2} \mathrm{Zn}_{3}$ phase in this alloy. Adding more than $1 \mathrm{~m} \%$ of $\mathrm{Ca}$ to the Mn containing alloy MX21 does not result in better sheet properties compared to the MX20 with less than $1 \mathrm{~m} \%$ of $\mathrm{Ca}$. Around $1 \mathrm{~m} \%$ of $\mathrm{Ca}$ added to the Al-Zn containing Mg-alloy ZAX210 leads to a texture close to those of rare earth $\mathrm{Zn}$ containing alloys like ZE10. The mechanical properties are as well comparable as they show high formability and a good strength. In the ongoing project two of the alloys (MX20 and ZAX210) will be processed via twin roll casting (TRC) and the process parameters will be tuned to optimize the resulting sheet properties.

\section{Acknowledgements}

This research was performed as a joint research project in the research program " ${ }^{3}$-Innovative Technologien für Ressourceneffizienz-Strategische Metalle und Mineralien" within the framework "Forschung für nachhaltige Entwicklung”. The project „Substitution of rare earth elements in high strength and ductile Magnesium sheet material - SubSEEMag" was financially supported by the German Federal Ministry of Education and Research

\section{References}

[1] Stutz, L., Bohlen, J., Letzig, D., Kainer, K.U.: Formability of magnesium sheet ZE10 and AZ31 with respect to initial texture, In Sillekens, W., Agnew, S.R., Mathaudhu, S. N. Neelameggham, N.R., Magnesium Technology 2011, Warrendale, The Minerals, Metals \& Materials Society TMS, 2011, $373-378$

[2] L. Stutz, J. Bohlen, G. Kurz, D. Letzig, K.U. Kainer, Key Eng. Mater. 473 (2011), p. 335 342.

[3] C.E. Dreyer, W.V. Chiu, R.H. Wagoner, S.R. Agnew, J. Mat. Process. Techn. 210 (2010), p. 37-47.

[4] K. Hantzsche, J. Wendt, K. U. Kainer, J. Bohlen und D. Letzig: Effect of process parameters and alloy composition on texture development and mechanical properties of magnesium sheets, JOM, 61, 2009, S. 43-47.

[5] J. Bohlen, M. Nürnberg, J. W. Senn, D. Letzig und S.R. Agnew: The texture and anisotropy of magnesium-zinc-rare earth alloy sheets, Acta Materialia, 55, 2007, P. 2101-2112.

[6] S.B. Yi, D. Letzig, R. Gonzalez-Martinez, K. Hantzsche, J. Bohlen, I. Schestakow und S. Zaefferer: Improvement of magnesium sheet formability by alloying addition of rare earth elements, Thermec 2009, Berlin (2009), P. 1506-1511.

[7] J. Bohlen, J. Wendt, M. Nienaber, K.U. Kainer, L. Stutz, D. Letzig: Calcium and zirconium as texture modifiers during rolling and annealing of magnesium-zinc alloys, Materials Characterization, Volume 101, April 2015, P. 144-152

[8] S. Yi, D. Letzig, K.U. Kainer, O.D. Kwon, J.H. Park and J.J. Kim, in The 10th international conference on $\mathrm{Mg}$ alloys and their applications, will be published

[9] V. Kree, J. Bohlen, D. Letzig, K.U. Kainer, "Practical Metallography 5", 2004, 233-246.

[10]F. Bachmann, R. Hielscher, H. Schaeben, "Texture Analysis with MTEX - Free and Open Source Software Toolbox", Solid State Phenomena (2010), 160, 63-68. 